\title{
INTERCULTURALIDADE EM QUESTÃO: ANÁLISE CRÍTICA A PARTIR DO CASO DA EDUCAÇÃO INTERCULTURAL BILÍNGUE NO CHILE*
}

Boris Ramírez Guzmán**

Resumo: Durante as últimas duas décadas, o conceito de Interculturalidade tomou uma importante força dentro do cenário das políticas públicas no Chile. Por um lado, os povos indígenas que coexistem dentro desta nação têm nela procurado o reconhecimento jurídico e seu poder de autonomia e autodeterminação; o Estado, com uma visão mais conservadora, por outro lado, tem investido em políticas focadas na inclusão desta população na estrutura societária do país. O presente artigo busca realizar uma leitura crítica do entendimento que faz o Estado Chileno ao perspectivar sua noção de Interculturalidade, procurando-se ponderar os deslocamentos epistemológicos e discursivos nos quais incorre a proposta de Educação Intercultural especificamente, estabelecida enquanto política focalizada para indígenas, mas, também, avaliando os riscos que isto pode significar dentro do quadro social do Chile contemporâneo. Este trabalho baseiase na discussão crítica das bases e subsídios teórico-jurídicos em que se estabelecem os elementos de Interculturalidade e Educação no Chile.

Palavras-chaves: Estado. Interculturalidade. Educação Intercultural Bilíngue. 
Resumen: Durante las últimas dos décadas el concepto de Interculturalidad ha tomado una importante fuerza dentro del escenario de las políticas públicas en Chile. Por un lado, los pueblos indígenas que coexisten dentro de esta nación, han buscado, en ella, el reconocimiento jurídico y su poder de autonomía y autodeterminación; el Estado con una visión más conservadora por otro lado, ha invertido en políticas que procuran la inclusión de esta población en la estructura societaria del país. El presente artículo busca realizar una lectura crítica del entendimiento del Estado Chileno al perspectivar su noción de Interculturalidad, ponderando los movimientos discursivos y epistemológicos en los que incurre la propuesta de Educación Intercultural específicamente, establecida como política focalizada para indígenas, pero también, evaluando los riesgos que esto puede significar dentro del entramado social del Chile contemporáneo. Este trabajo se basa en la discusión critica de las bases y subsidios teóricos-jurídicos en los que establecen los elementos de Interculturalidad y educación en Chile.

Palabras-claves: Estado. Interculturalidad. Educación Intercultural Bilingüe. 


\section{Introdução}

No contexto mundial, e particularmente no latino-americano, a interculturalidade desempenha um importante papel ao olhar para as relações de alteridade e assimetria, propondo uma série de transformações jurídicas que buscam a inclusão da população indígena e afrodescendente. Nos últimos trinta anos, além das discussões teóricas que surgiram para abordar esta problemática, o contexto jurídico internacional centrou esforços em construir uma série de normatividades que apontam à promoção da diversidade, multiculturalidade e interculturalidade. Essas normatividades são representadas por uma série de declarações e convenções que os Estados nacionais subscrevem, reconhecendo as diversidades étnicas e culturais que coexistem em seu seio, por meio de um papel protagonista como fiador e promotor, assumindo deveres, bem como outorgando direitos à diversidade dos povos que o conformam.

Assim, no âmbito internacional, nasce em 1989 o "Convênio 169” sobre povos indígenas e tribais, por meio da Organização Internacional do Trabalho (OIT). Este convênio, principalmente nos países latino-americanos, tornou-se uma das principais referências dos povos indígenas na luta pelo seu reconhecimento no contexto dos Estados-Nacionais. Em 2007, a assembleia geral da Organização das Nações Unidas (ONU) aprovou a declaração de direitos dos povos indígenas. A sua subscrição, ratificação e implementação em cada um dos países da região aconteceu de forma distinta e gerou movimentos e dinâmicas diferentes. Contudo, é importante considerar que esses convênios se transformaram no sustento não só da demanda por parte dos povos indígenas por In- 
terculturalidade, mas também de linhas de ação para muitos dos países nessa matéria. Dentro destes movimentos, uma das áreas mais interpeladas, como um dos eixos centrais nestas políticas de reconhecimentos, foi a "Educação".

\section{Educação, interculturalidade e seu marco jurídico no Chile atual}

Apesar de a questão indígena ser um conflito constante no Chile, foi somente durante os últimos vinte anos que se realizou uma série de reformas que dão sinais de reconhecimento da diversidade étnica e geração de uma política reparatória após anos de extermínio e invisibilização dos povos originários.

A partir da promulgação em 1993 da lei 19.253, mais conhecida como a "Lei Indígena", da declaração dos direitos indígenas da ONU em 2007, do convênio 169 da OIT, que embora promulgado em 1989 só entrou em vigência em 2010, estabelecemos um marco geral que se atém ao âmbito da educação no Chile.

A “Lei Indígena”, conquanto possua muitas controvérsias pelos vazios de representatividade, participação e consulta efetiva dos povos indígenas, foi a primeira lei neste novo processo democrático (pós-ditadura) que abordou essencialmente o seu reconhecimento e desenvolvimento. Este novo reconhecimento estipulado pelo Estado fica consagrado especialmente em seu primeiro artigo que estabelece:

O Estado reconhece que os indígenas do Chile são os descendentes das agrupações humanas que existem no território nacional desde tempos pré-colombianos, que 
conservam manifestações étnicas e culturais próprias sendo para eles a terra o fundamento principal de sua existência e cultura. ${ }^{1}$

A lei propõe como papel do Estado, em particular, e da sociedade em geral proteger e promover o desenvolvimento dos povos indígenas e sua cultura, adotando e potenciando mecanismos e instituições para concretizá-lo. Para tais efeitos, esta lei cria a Corporação Nacional de Desenvolvimento Indígena (CONADI), uma instituição estatal de serviço público, entidade jurídica autônoma e de patrimônio próprio, que será fiscalizada pelo Ministério de Planejamento (MIDEPLAN) e que poderá em nome do Estado promover, coordenar e executar ações a favor do desenvolvimento de pessoas e comunidades indígenas nos âmbitos econômico, social e cultural. Sobre este último ponto, a lei estabelece na alínea $\mathrm{b}$ do artigo $38^{\circ}$ que a CONADI terá entre suas funções promover as culturas e idiomas indígenas e sistemas de educação intercultural bilíngue (EIB) em coordenação com o Ministério de Educação (MINEDUC).

Não obstante, no texto desta lei, composta de oitenta artigos, podemos dizer que a noção de interculturalidade é vaga. É digno de nota que já no seu artigo primeiro estabelece o reconhecimento de nove etnias, mas não de povos. Este elemento, talvez apenas retórico como pareceria a princípio ser, na realidade coloca em tela de juízo o tipo de reconhecimento de que estamos concretamente falando. Sem dúvida, estabelecer um reconhecimento jurídico apenas de etnia é uma manobra política que deixa amarrados à vontade estatal os conceitos de autodeterminação e autonomia (é importante enfatizar que isto não implica independência, apenas a possibilidade dos povos decidirem os modos e mecanismos para 
guiar politicamente suas vidas). Segundo o direito internacional, a partir da carta das Nações Unidas de 26 de junho de 1945 e dos Pactos internacionais de direitos humanos de 1966 adotados no seio da ONU estabelece-se dentro do cenário do direito internacional o conceito de "Livre determinação" ou "Autodeterminação" dos Povos e o status de igualdade de direitos de homens e mulheres perante a lei. Determina-se como uma das normas do direito internacional público, o direito de um povo a decidir suas próprias formas de governo, perseguir seu desenvolvimento econômico, social e cultural e estruturar-se livremente sem ingerências externas e de acordo com o princípio de igualdade ${ }^{2}$. Embora a gênese do reconhecimento de "Povos" e, portanto, de sua "Autodeterminação" esteja contextualizada a partir dos processos de descolonização da África e Ásia, produto da Segunda Guerra Mundial, houve também um forte eco nos povos indígenas, que se veem ainda colonizados dentro da jurisprudência própria dos Estados Nacionais latino-americanos que não reconheciam ainda seus direitos nem suas formas de vida e organização.

A partir disto, surgem três questões fundamentais que nortearão as próximas seções deste artigo, que são: $\mathrm{O}$ que o Estado entende e propõe por interculturalidade e educação intercultural bilíngue? Por que a interculturalidade e a Educação Intercultural Bilíngue só se apresentam como política focalizada? Então, falamos de: Uma interculturalidade para quem? Estas questões são fundamentais para examinar as hipóteses que o estado chileno estabelece em matéria educacional, à luz dos ditames do marco jurídico nacional.

Seguramente, tal questionamento reflete a complexidade da questão indígena no Chile e sua abordagem. Claro exemplo dis- 
to foi a conflituosa e tardia entrada em vigência do convênio 169 da OIT, passados vinte anos de sua promulgação (1989-2009)3․ O convênio 169 é um instrumento jurídico internacional que atribui conceitos básicos de respeito, reconhecimento e participação. Estabelece o direito dos povos indígenas a definir suas prioridades sobre o desenvolvimento, o caráter de consulta de boa fé aos povos indígenas com respeito a medidas legislativas que os afetem, e consagra meios de participação em instituições e organismos responsáveis por políticas e programas que os concernem. Dita que a justiça nacional deverá considerar os costumes ou o direito consuetudinário próprio dos povos indígenas, estabelecendo procedimentos para solucionar os conflitos entre ambos os sistemas. Um ponto discordante com a Lei Indígena do Chile é que o Convênio propõe aos governos reconhecer a importância das terras indígenas, assumindo que o conceito de "terra" inclui o de "território", também estipula que os recursos naturais existentes em terras indígenas deverão ser protegidos e que os povos deverão ser consultados antes da prospecção ou exploração dos recursos do subsolo. Todos estes direitos não figuram na atual Lei Indígena 19.2534.

Dentro do cenário do direito público internacional, outra declaração que trata dos direitos indígenas é a declaração das Nações Unidas sobre os direitos dos povos indígenas de $2007^{5}$. O artigo $14^{\circ}$, igualmente ao que dispõe a OIT, propõe uma educação pertinente e gerenciada principalmente pelos próprios povos indígenas, bem como o desenvolvimento de suas línguas. A Declaração dos Direitos dos Povos Indígenas se estabelece juridicamente dentro das normas do direito internacional e consuetudinário. Discute-se copiosamente se esta declaração de direitos é vinculante, pois ela possui um status jurídico diferente de uma convenção ou tra- 
tado internacional, o qual deve ser ratificado pelos parlamentos dos países. Porém, José Aylwin (2010) afirma que existem argumentos poderosos para assumi-la como vinculante, baseando-se nos juristas estadunidenses James Anaya e Siegfried Wiesser. Para ver as implicações desta declaração no direito internacional e consuetudinário, é importante considerar a representatividade que possui esta declaração, e neste caso foram somente quatro os países que votaram contra (Estados Unidos, Canadá, Austrália e Nova Zelândia), o que não invalidaria sua implementação dentro da normatividade internacional.

Levando em consideração o que dispõem estes três documentos jurídicos, podemos realizar abaixo as seguintes considerações para ver como se perspectivam a interculturalidade e a educação no Chile (RAMIREZ, 2012).

Quanto ao reconhecimento jurídico dos povos indígenas, trata-se ainda de um processo inacabado. Segundo o artigo primeiro da Lei Indígena, estes são reconhecidos apenas como etnia, negando-lhes a denominação de "Povo" e "Territorialidade", o que implicaria um reconhecimento dentro do direito internacional e consuetudinário que lhes brindaria o direito de autodeterminação, segundo o disposto na carta da Organização das Nações Unidas, nos pactos internacionais de Direitos Humanos da ONU, na Declaração dos direitos dos povos indígenas da ONU e no que dispõe a Convenção 169 da OIT. Embora se lhes conceda o direito de igualdade por intermédio da nacionalidade e cidadania chilena, o direito à diferença (e a seu exercício) e à autodeterminação se lhes nega.

É interessante comparar o que o Estado do Chile delineia como educação por meio da lei indígena com o que propõem 
os instrumentos internacionais da OIT e da ONU. O Estado do Chile propõe uma Educação Intercultural Bilíngue, mas chama a atenção que essa interculturalidade e esse bilinguismo se articulem como uma política focalizada, isto é, só para a população indígena e só em áreas de alta densidade indígena. Assim sendo, a pergunta que deriva é: Onde está materializada essa interculturalidade? É curioso pensar que o Estado propõe uma educação intercultural sem ser capaz de mudar o status jurídico que o centra como um Estado monocultural, que reconhece somente um povo, o chileno. Por outro lado, o que me parece perigoso, o entendimento de interculturalidade que o Estado estabelece é o de uma interculturalidade unidirecional, ou seja, a interculturalidade proposta é somente uma interculturalidade para o indígena. Apresenta-se a convergência de dois mundos, o próprio (indígena) e o chileno ocidental, porém se exime de representar essa interculturalidade dentro da educação pública, ou seja, a educação de chilenos. Parece-me que isto busca estabelecer-se como a ideia de um falso positivo por meio de um exercício retórico que professa uma interculturalidade que se despedaça por si só, pelo seu pobre suporte teórico e jurídico, estabelecendo um tipo de controle social ao minimizar e esconder os verdadeiros conflitos étnicos e culturais que ainda existem em matéria de educação.

A noção de interculturalidade proposta pelo Estado cai nesta espécie de falso positivo também porque centra seu exercício somente no âmbito e competência da educação e não dimensiona as verdadeiras características jurídico-ético-políticas que correspondem ao Estado na transformação dos aparatos jurídico, político e econômico que estabelecem a continuidade de mecanismos de subalternização dos povos indígenas no Chile. 
Dentro das categorias definidas para entender a interculturalidade a partir das contribuições de Walsh (2005), podemos dizer que segundo o que a lei indígena apresenta, a noção de interculturalidade que dela emana está dentro do que se define como "Interculturalidade Referencial", por substantivar a interculturalidade como uma ação que está dada, e não conseguir vê-la como processo multidirecional. Não muda substancialmente as relações culturais nem éticas, dentro dos grupos ou povos que coexistem entre si, homogeneizados, sob a mesma nomeação jurídica, não possibilitando o fluxo multidirecional dentro do processo educativo. Invisibiliza as relações de poder existentes e não consagra uma alteridade simétrica.

O Estado propõe ironicamente uma interculturalidade que juridicamente carece de mais um interlocutor, pois em teoria, segundo o que a constituição da república do Chile define e o que a Lei Indígena em particular especifica, só existe o povo chileno, então: Com qual ou quais outros povos se consumaria uma prática intercultural?

O processo educativo que a Lei Indígena projeta é precisamente educação indígena e não educação intercultural. A educação indígena é importante dentro dos processos de revitalização dos povos, mas perde valor substancial quando é construída apenas pelo Estado, pois sua pertinência pode ficar presa pela ótica homogeneizadora própria do papel do Estado. Os instrumentos da OIT e das Nações Unidas falam de educação indígena e não educação intercultural. Falar, pois, de interculturalidade supõe uma transformação importante dentro dos marcos constitucionais dos Estados Nacionais. Isso não toca necessariamente só o âmbito educacional. Por isso enfocam seus esforços em gerar uma 
educação de pertinência em função da conformação étnico-cultural no interior dos Estados Nacionais, propondo uma educação indígena que seja apoiada inicialmente pelo Estado e que, progressivamente, comece a ser dirigida pelos próprios povos.

Sob este aspecto, a revitalização das línguas é fundamental, pois é um dos veículos mais pertinentes que os povos têm para poder reapropriar sua cultura e dinamizá-la. Embora a lei indígena, o convênio 169 e a declaração das nações unidas admitam a importância de sua revitalização, dispondo seu ensino, investigação e difusão, as línguas ainda não estão protegidas por nenhum marco jurídico constitucional e continuam sob um status de hierarquia. São estabelecidas línguas mais importantes, como a oficial, e outras de caráter inferior, como as indígenas. Esta geopolítica linguística ainda imperante sem dúvida é um dos obstáculos mais importantes, além do jurídico, para estabelecer relações de alteridade maduras, porque, além de geopolitizar modos comunicativos, marginaliza mundos também.

\section{Desdobramentos da educação intercultural bilíngue no Chile}

Segundo o que dispõe o artigo $32^{\circ}$ da Lei Indígena, o estado se compromete a desenvolver um sistema de Educação Intercultural Bilíngue (EIB) para preparar os educandos indígenas ao seu desenvolvimento tanto em sua sociedade de origem quanto global. Esta disposição insere-se dentro de reivindicações próprias que os povos indígenas tiveram por anos frente ao Estado do Chile. Materializa-se por fim legalmente sob o algeroz desta lei. Assim, inicialmente junto com a criação da CONADI, a partir de 1996 se levam 
a cabo os primeiros programas experimentais de EIB dentro do programa de educação básica rural do Ministério de Educação, para finalmente definir como realizar o "Programa de Educação Intercultural Bilíngue" (PEIB) ${ }^{6}$.

De acordo com os dados do próprio Ministério de Educação, do total das escolas rurais do país, 261 se encontram focalizadas pelo Programa de Educação Intercultural Bilíngue (PEIB), o que representa um 6.2\% do total das escolas. Dentro do total das escolas focalizadas 196 escolas têm mais de 50\% de matrículas de alunos indígenas, representando $75.1 \%$ do total de escolas focalizadas (261) e 4.7\% do total das escolas rurais do país. (MINEDUC, 2011)

Segundo o censo do ano de 2002, cerca de 65\% da população indígena vive em área urbana. De acordo com a CONADI, atualmente este número aumentou para 70\%, e meios extraoficiais estipulam que os indígenas urbanos se aproximam de $80 \%$. Ou seja, podemos dizer que o PEIB além de ser um programa focalizado em indígenas, foca especificamente indígenas rurais, e estes representam aproximadamente apenas um terço da população indígena total do Chile. Chama a atenção que nos eixos para o desenvolvimento de um modelo educacional intercultural estão ausentes o resto da comunidade nacional, o que perfila desde antemão estes delineamentos como a criação um modelo de educação particularmente indígena. Além de reconhecer-se como uma política focalizada, este foco novamente se afila, já que o público estudante alvo da EIB só está contemplado nos quatro primeiros anos de escolaridade, como demonstram os programas de estudos que foram emitidos pelo MINEDUC.

Dentre os documentos publicados pelo MINEDUC sobre o PEIB, muitos dão a conhecer qual é o seu entendimento teórico 
de interculturalidade e educação. Mas um em especial tem sido o documento matriz sobre cujos supostos se levanta esta proposta educativa. Trata-se de um documento de 2002, intitulado "Aspectos gerais da educação intercultural bilíngue e seus fundamentos" do qual se valerão, de forma quase integral, os outros documentos emitidos pelo PEIB. No texto se dá a conhecer o que se entende primeiramente por interculturalidade, realizando uma abrangente contextualização histórica e teórica para definir o termo. Neste sentido, a interculturalidade é contextualizada como uma demanda própria dos indígenas, como consequência do projeto colonizador e civilizador que viveram estes povos em toda a América. Considera-se que o estabelecimento desta nova ordem civilizatória trouxe consigo a dicotomia de considerar os povos indígenas como bárbaros por meio da submissão, impondo assim o domínio da cultura e da língua. Entende-se que esta submissão se faz presente nas relações interétnicas através dos princípios do autoritarismo, negação do outro, imposição e despojo mediante força, gerando uma relação etnocêntrica por parte da cultura civilizada, como foi o caso da América. A interculturalidade neste sentido se instala reconhecidamente como um tema central para os povos indígenas pela necessidade de mudar essas relações de submissão e assimilação de que foram vítimas. Observa-se que:

São estes povos (os indígenas), e seus direitos fundamentais, os que justificam com sua presença (e buscam com urgência), o estabelecimento de relações interétnicas de cooperação no marco dos Estados nacionais. Relações baseadas no respeito mútuo, reconhecimento e aceitação do outro como legítimo outro na convivência, diálogo, comunicação, reparação e reciprocidade. A origem da interculturalidade está nas aspirações de desenvolvimento dos povos que viveram uma longa história de conflito e dominação, que 
desejam que se termine, de uma vez por todas. (CAÑULEF, GALDÁMEZ, MINEDUC, 2002, p. 28).

Como primeiro contraponto a ressaltar está o papel que os Estados Nacionais desempenham no entendimento das perspectivas da interculturalidade. Pois as relações de cooperação, de reconhecimento do outro e de aceitação se apresentam como diálogo próprio dos marcos estatais, mas sem especificar se este reconhecimento, respeito e cooperação podem materializar-se por intermédio da autodeterminação dos povos, excedendo o papel tutelar do Estado.

O documento analisado propõe que a essência da interculturalidade é a cooperação na busca da justiça, igualdade, fraternidade e liberdade, como formas de superar o medo ao outro. Estabelece que a interculturalidade deve reger-se por 6 princípios básicos apresentados como: 1) Aceitação da alteridade, definida a partir da condição humana de sentir-se diferente e de aceitar a diferença do outro, legitimando-o como é, para construir relações de convivência saudáveis que nos permitam coexistir e crescer juntos; 2) A conversação como uma forma dialógica e de negociação dentro da sociedade; 3) A comunicação, que deixe de lado as formas de imposição e de dominação, entendida como forma de participação dos grupos étnicos minoritários, como mecanismo que possa dar a conhecer ao Estado suas aspirações e chamar a atenção deste quando lese seus interesses e direitos; 4) A flexibilidade, como resposta a atitudes autoritárias que se evidenciam na arrogância, despotismo e teimosia, permitindo gerar relações de cooperação interétnicas; 5) A reparação, considerando-se que as relações de cooperação não podem estabelecer-se a partir de situações de injustiça. Nesse sentido a reparação é base importante nas relações 
de cooperação, compreendidas não somente em seu aspecto material, mas também cultural e espiritual; 6) E, finalmente, a Reciprocidade, como princípio básico dentro desta lógica de cooperação, e de imbricações indígenas muito profundas, reconhecendo que estas relações devem estar baseadas no dar e receber como forma fecundante de qualquer relação, seja entre indivíduos, sociedades, estados ou meio ambiente.

É interessante observar como esse entendimento de interculturalidade se estabelece. Embora o texto seja produto do esforço de um grupo interdisciplinar de pessoas indígenas e não indígenas, ele apresenta uma forma superficial de pensar a interculturalidade. Pois apesar de tocar pontos importantes para entender como ela se articula desde práticas históricas e políticas, faz isso de uma forma global e em terceiras pessoas, "as sociedades", “os Estados”, invisibilizando as assimetrias que ainda se exercem em todos os âmbitos com os povos indígenas. Também propõe um entendimento limitado do aspecto multifocal da interculturalidade ao estabelecê-la apenas desde uma ótica relacional social, e não como uma forma estrutural de dominação. Desconsidera o aspecto político, como, por exemplo, na livre determinação dos povos, ou o econômico, que se desprende a partir da desterritorialização, alegando que o intercultural se conquista apenas desde o atitudinal, ou seja, desde uma mudança de atitude para com o "Outro".

Embora dentro dos eixos estabeleça como central a questão da reparação e justiça, pelo que se desprende do texto em sua totalidade esta aponta uma reparação mais de caráter moral e não elementar dentro dos âmbitos violados por séculos, sem questionar quais são as travas e as práticas sociais, políticas e econômicas que na atualidade continuam estabelecendo a subalternização. 
Pois bem, como se entrelaça esta noção de interculturalidade com educação nos marcos do PEIB? O documento expõe que:

Conceber um processo educativo intercultural planificado significa assumir a interculturalidade como seu princípio reitor, o que a sua vez implica não só o reconhecimento da heterogeneidade social, étnica e de 'racionalidades' de seus diversos agentes, mas também exige uma práxis pedagógica que conduza à gestão de um autêntico democrático, consciente dos direitos e deveres de cada qual como indivíduo, como grupo ao que pertence, e também dos deveres e direitos dos demais. (CAÑULEF, GALDÁMEZ, MINEDUC, 2002, p. 33).

Aceita-se que em uma educação intercultural é imprescindível a conjugação de dois elementos, o reconhecimento da diferença e uma prática pedagógica que a guie como um exercício democrático. Para isto, propõe-se reconfigurar e contextualizar o currículo às particularidades socioculturais dos educandos, o que se materializa em conteúdos que interpelem o conhecimento próprio dos povos em questão, sem cair, contudo, nos conteúdos essencialistas que pressupõem realidades antigas e fixas. Entende-se que os povos e seus conhecimentos são dinâmicos e sofreram transformações durante o decorrer do tempo. Para abarcar isso, pressupõe-se a incorporação de educadores tradicionais no processo pedagógico, a incorporação de programas e planos de estudos que sejam bilíngues, a adaptação da escola aos ciclos produtivos de semeadura e colheita das comunidades, a participação e o diálogo constante da comunidade com a escola, bem como a incorporação de suas práticas rituais.

Por outro lado, admite-se que neste cenário a revitalização de línguas e uma educação bilíngue se justificam pelo profundo 
processo de castelhanização que viveram os povos indígenas. $\mathrm{Da}$ mesma forma que pela exclusão, pela inferiorização de status dentro da escola, da administração pública, e dos meios de comunicação, que sustentaram sua negação linguística. Isso tem como consequência o confinamento só a uso intrafamiliar e ritual, a aculturação linguística evidenciada na substituição de fonemas e palavras desde o castelhano, a modificação morfossintática da língua, o monolinguismo castelhano principalmente entre jovens, a debilitação e perda da lealdade linguística que se expressa no não ensino às novas gerações (CAÑULEF, GALDÁMEZ, MINEDUC, 2002). Finalmente, há de se levar em consideração que uma EIB deve necessariamente se preocupar desta situação de diglossia em que se encontram as línguas dos povos indígenas, de modo a gerar estratégias para revalorizá-las e ensiná-las.

Neste sentido, a estratégia proposta consiste em mudar, na escola, o enfoque de um "Bilinguismo Subtrativo", onde historicamente os estudantes vinham com alguma base de suas línguas maternas, mas que com o constante uso do castelhano, estas se deslocavam e perdiam importância, chegando por vezes ao esquecimento. Faz-se necessário assumir um "Bilinguismo Aditivo", onde o ensino da segunda língua não busque substituir a língua materna e busque desenvolver nos estudantes competências comunicativas e linguísticas equiparáveis e adequadas em ambos os idiomas.

Em um documento posterior para orientações na contextualização dos planos e programas de EIB, o MINEDUC desenvolve e agrega que a opção tomada para entender interculturalidade, frente à gama de entendimentos que se desenvolveram em toda América Latina, é baseada em duas concepções. Uma, a explicativa, com base na interculturalidade como atributo e compreensão 
das relações interétnicas realmente existentes, onde a interculturalidade é entendida como o produto do contato entre culturas independentes das relações dominantes existentes. Orienta-se que esta postura não é a que se busca como programa, pois não trata dos verdadeiros conflitos socioculturais e não aposta na redignificação da identidade dos indígenas e, portanto, não se pode conceber uma EIB a partir disto (MINEDUC, 2005). O segundo entendimento que apresentam é centrado como uma concepção paradigmática, que considera a interculturalidade como atributo das relações interétnicas de cooperação, definida como:

Nesta noção, a interculturalidade é concebida como um novo paradigma que dá conta da existência de várias culturas dentro de uma comunidade maior, a sociedade ou o Estado. É um conceito que se emprega com um valor neutral, é dizer, não implica relações hierárquicas, mas postula um paralelismo cultural com igualdade de direitos. É uma utopia em construção, uma nova forma de convivência entre os povos sustentada no respeito às diferenças, no reconhecimento da multiculturalidade mundial e nacional, que contribui à construção de nações de novo tipo: pluriétnicas, multiculturais e plurilíngues. A interculturalidade aparece, então, como um projeto democratizador. (CAÑULEF, GALDÁMEZ, MINEDUC, 2005, p. 23).

É interessanteler as entrelinhas deste parágrafo, pois evidenciam com claridade aquilo que em diferentes textos Walsh (2002, 2005, 2008) denomina como "Interculturalidade Funcional", onde se propõe um falso positivo de igualdade, todavia, sem mudar as estruturas ou as "regras do jogo", como diz a autora, que provocam a assimetria e a subalternização. Isso fica em evidência neste texto quando observamos que a interculturalidade é entendida como 
uma prática que se dá em nível de alteridades de comunidades étnicas (nações) e não por meio de figuras jurídicas cristalizadas do Estado. As nações existiam muito antes que existissem os estados nacionais, conflitos entre elas também, mas esses conflitos, invisibilizações e negações se instauram jurídica e politicamente com a conformação dos estados nacionais.

Temos um claro exemplo disso na Espanha, onde o estado se ergueu sobre diferentes nações (com culturas, histórias, territórios e línguas próprias) como o povo galego, asturiano, catalão, e talvez mais visivelmente por sua luta o povo basco, que ficou dividido entre dois estados, o francês e o espanhol. Durante anos, especialmente durante a Espanha de Franco, esses povos lutaram por um reconhecimento de suas nações e contra a política assimiladora do Estado através da castelhanização. O estabelecimento de políticas multiculturais e pluriétnicas, neste sentido, não se constitui em uma inflexão fundadora para conceber o Estado, é mais bem um adjetivo qualificativo que se lhe ostenta, em que a diversidade homogeneíza a diferença, porque esta última não é consagrada em termos jurídicos como tal.

Um exemplo contrário são os processos vividos durante a última década no Equador e na Bolívia, onde também coexistem várias nações. A solução que encontraram para romper os marcos estruturais que negavam essa outridade, foi realizar uma refundação do Estado Nacional, e concebê-lo como Estado Plurinacional, onde territórios, língua e educação por antonomásia se assumem interculturais, pois necessitam harmonizar-se com a estrutura jurídica estatal plural da qual fazem parte.

O que quero dizer com isto é que, apesar de que o suposto de interculturalidade não busque ampliar relações hierárquicas e que 
diga ser neutro, como no texto citado, isto não é assim. Pelo contrário, possui uma enorme intencionalidade de forma e fundo, pois a hierarquia se materializa no não reconhecimento pleno das identidades, situando-as apenas como horizontes culturais coexistentes, subordinados sob um conceito único, fixo e fechado. Um claro exemplo disso se vê refletido em dois dos povos do Chile que se reconhecem justamente como nação, como é o caso Mapuche, que leva anos pedindo sua autonomia e autodeterminação, e o povo Rapanui, que pese a invisibilidade que realiza o Estado do Chile produto de sua lonjura geográfica, intensifica o conflito com o Chile durante a última década solicitando sua independência. Isto é assim (entre muitas coisas mais) porque a interculturalidade que o Estado propõe não se faz com base em flexibilizar ou transformar sua estrutura, pois continua a exercer mecanismos de dominação política, econômica, cultural etc. O resultado que acarreta é que os outros povos e/ou nações que constituem o Chile não se sentem refletidos nessa construção de Estado uninacional. Boaventura Santos dá uma contribuição importante para entender isto ao afirmar que:

A simetria liberal moderna - todo o Estado é direito e todo direito é do Estado - é uma das grandes inovações da modernidade ocidental. É também uma simetria muito problemática não somente porque desconhece toda a diversidade de direitos não-estatais existentes nas sociedades, mas também porque afirma a autonomia do direito em relação com o político no mesmo processo que faz valer sua validez do estado. (SANTOS, 2010, p. 88).

Essa diversidade que se professa no entendimento de interculturalidade é uma diversidade presa e delimitada dentro do 
Estado de direito. O Chile, entre suas muitas particularidades só reconhece uma nação, a chilena, e só reconhece um povo, o chileno, que se constitui por uma diversidade que não goza de nenhum status jurídico nem representação política, porque é assimilada por esta estrutura maior definida como "o chileno". Este é estabelecido como o único modo funcional para que essas diversidades coexistam. Outro exemplo disso se materializa quando o Estado define o impacto da EIB, considerando que:

Desde o ponto de vista dos povos indígenas a educação intercultural bilíngue será o modelo educativo que lhes permitirá exercer o direito natural a aprender sua língua e, através dela, conectar-se com o fundamental de sua cultura de origem e, ao mesmo tempo, aprender a língua nacional que lhes há de servir para conhecer e manejar os códigos culturais da sociedade nacional. (MINEDUC, 2005, p. 28, itálico nosso).

Determinando que a EIB se concebe como um modelo que reafirma as identidades indígenas, mas também a nacional (chilena) que permanecerá imutável, pois o programa é unidirecional e não prevê como a comunidade nacional também se reafirmará a partir da questão indígena nesta trama de diversidade que professa.

Em ambos os documentos do MINEDUC (2002, 2005), aparece outra coisa que não é menor para entender a dimensionalidade desde onde o programa se situa. Estabelece-se que o espírito da EIB é entendido pelo baixo rendimento que apresentam os estudantes indígenas, justificando-se por uma questão de qualidade de educação, e quando distingue em que consiste isto, aparece o tema de reafirmação da identidade. É importante mencionar isto, pois nos permite ver o motor que norteia esta aposta em melhores resultados 
educativos, que não garantirá a revalorização e revitalização da cultura, mas a apropriação ou empoderamento da cultura nacional. A prova SIMCE (Sistema de Medição da Qualidade da Educação) que mede os conhecimentos e habilidades que os estudantes desenvolvem contempla apenas a cultura nacional. Ou seja, pode-se pensar de forma leviana, e por vezes não tão injustificadamente, que a EIB é uma estratégia. Busca, por meio dos códigos culturais próprios, dentro de sua transversalidade, reafirmar a identidade étnica e cultural do estudante. Porém, busca, através dela, que o sujeito possa entender e incorporar-se à cultura nacional, ou seja, uma estratégia assimiladora mais humanizada, que conquanto não negue atitudinalmente a identidade, processualmente tampouco a outorga.

Por outro lado, como forma de dar um maior sustento ao desenvolvimento do Bilinguismo dentro do contexto da EIB, em 22 de setembro de 2009 se emite o decreto supremo de educação n. 280, o qual dispõe a criação do setor de aprendizagem (disciplina) de Língua Indígena, incluindo-o assim ao Marco Curricular de educação e estabelecendo Conteúdos Mínimos Obrigatórios e Objetivos Fundamentais para seu desenvolvimento durante toda a educação básica. Este setor de aprendizagem está em fase de aplicação há pouco tempo, começou a ser implantado em 2010, como obrigatório para o primeiro ano básico, em 2011, para o segundo básico, em 2012 para terceiro básico e assim deverá seguir, sucessivamente. $\mathrm{O}$ artigo $4^{\circ}$ do decreto 280 estabelece que este setor de aprendizagem está à disposição de todos os centros educativos que queiram contribuir à interculturalidade, mas que para os alunos será de caráter opcional cursá-lo. Não obstante, em seu artigo $5^{\circ}$ determina que para todas as escolas que tenham uma matrícula de $50 \%$ de estudantes de ascendência indígena será obrigatório oferecê-lo a partir de 2010, e para as que apresentam 
entre 20 e $49 \%$ a partir de 2013.

Não me sinto capacitado em realizar uma análise sobre a pertinência e as formas metodológicas com que se desenvolverá este setor. Sinto que isso é mais atributo dos linguistas, antropólogos e dos próprios indígenas que possuem conhecimento de suas línguas e culturas. Além disso, sem dúvida será um programa que há de ter seus ajustes, ainda está em forma experimental, em caráter facultativo, para todas as escolas focalizadas do país, e não há nenhuma geração que tenha cursado os oito anos deste setor. Só me cabe considerar que é uma iniciativa que se valora dentro do que estabelecem os marcos jurídicos sobre a língua e cultura indígena. Vejo como assertivo que se busque a incorporação de educadores tradicionais para o desenvolvimento deste setor, pois penso que só eles ou elas podem dar a contextualização e pertinência necessárias, e parece-me uma proposta coerente dentro de uma política visando à EIB.

Preocupa-me sim o pouco valor que ostenta este setor de aprendizagem frente aos outros dispostos no currículo. Sinto que o caráter de opcional é um fator que pode mermar bastante seu êxito e sua situação de gueto frente ao contexto nacional, resultando apenas como setor para grupos ainda mais focalizados. Atrevo-me a dizer que visto o status jurídico das línguas no Chile, o maior impacto que pode ter esta política é gerar estudantes bilíngues passivos. Isto pela incapacidade da cultura nacional de entender minimamente estas línguas, a pouca planificação de continuidade na educação média e superior, a existência de avaliações em castelhano na maioria dos setores de aprendizagem, incluso as avaliações padronizadas como a SIMCE, e ainda o próprio funcionamento jurídico e administrativo da sociedade. Finalmente, cabe notar que a maioria da população indígena se encontra em diáspora nos nú- 
cleos urbanos, representando mais de $70 \%$ do total dos indígenas, o que representa um cenário complexo para poder desenvolver social e cotidianamente o uso da língua de forma ativa.

\section{Educação intercultural ou educação indígena?}

A EIB no Chile, bem como no contexto latino-americano em geral, é uma prática política que a cada dia se faz mais presente para abordar a questão indígena. Seu desenvolvimento dentro do contexto chileno responde à normatividade tanto local quanto internacional que se desenvolveu para atender principalmente a este setor da sociedade. Porém, a leitura que o Estado Nacional realizou se apresenta como uma forma ambígua de entender a interculturalidade, fazendo vários deslocamentos discursivos e paradigmáticos. Assumir a interculturalidade desde uma ambiguidade epistemológica é complexo, pois acarreta uma práxis de caráter paliativa, ou seja, de trabalhar com os que ficaram à margem do processo civilizatório e de colonialidade. As causas desta marginalização, todavia, não apresentam relevância e, de fato, como pudemos apreciar, o resto da trama social, política e jurídica fica quase intacta, o que pode levar posteriormente a três consequências:

- Tomar a interculturalidade uma política focalizada apenas para indígenas, pois eles não foram capazes de adaptar-se à modernidade de outrem. A marginalização e a precariedade são os eixos que a EIB busca trabalhar, pois toma a identidade própria como código didático para que eles possam alcançar um grau de apropriação maior da cultura nacional e possam desenvolver-se nela, superando assim os estados periféricos em que se constituíram por não se desprender totalmente de sua identidade e cultura. 
- Pensar que criar relações de interculturalidade é responsabilidade somente do mundo indígena, em que a construção da diversidade cultural de um país está dada na medida em que eles possam reafirmar-se como cultura e desde aí integrar-se a uma trama social, dentro de uma sociedade que não está preparada para acolhê-los. Esta relação de interculturalidade e de alteridade busca reivindicar vítimas e não estruturas vitimárias.

- Estabelecer que a educação e, portanto, a escola é a responsável por criar e potenciar a interculturalidade, sendo que esta não tem a jurisprudência nas áreas da política e economia que deve dar o sustento na busca desta construção. Assim sendo, a escola só pode ter uma abrangência dentro do plano mais atitudinal e valorativo, mas que merma à sua vez por seu reduzido impacto com o perfil de população à qual vai dirigida a política intercultural.

Significa que a EIB é um erro? Erro não é, sem dúvida, é um imperativo que os povos indígenas possam ter uma educação mais contextualizada e pertinente, é quase um dever ético de qualquer prática pedagógica, como todos nós professores sabemos. Mas ao estabelecer este processo educativo como "Educação Intercultural" estamos lidando com expectativas das quais o programa não pode fazer-se cargo, pelo pouco impacto que abarca e pela incompetência que tem a educação, como tal, em modificar as próprias estruturas que causaram esta assimetria. Na matriz da colonialidade, a educação foi só um dos tantos meios de subalternização, mas não o motor desta, mais bem uma estratégia. Enrique Antileo realiza uma contribuição bastante iluminadora neste aspecto enfatizando que:

A interculturalidade no Chile se dá hoje em dia em uma situação colonial, onde uma cultura tem todas as 
ferramentas, como é a chilena, para poder perpetuar-se; e as outras como a nossa encontram-se só sobrevivendo. (Depoimento fornecido por liderança do povo indígena Mapuche em outubro de 2011). (RAMIREZ, 2012, p. 155).

Neste sentido, devemos fazer a diferença entre "Educação Intercultural" que supõe um tipo de educação com supostos já consumados, com outra que seja "Educação para a Interculturalidade", onde esses supostos se instalam como desafios a conquistar, e onde possamos gerar, assim, mecanismos de reprodução e criação das culturas de todos os povos que conformam o Chile. É por isso que é imprescindível assumir as limitações estruturais que a EIB ostenta, e não pretender mais do que realmente se pode fazer, assumindo-a pelo que realmente é, Educação Indígena. Uma educação indígena se estrutura mais coerentemente com o que propõe a lei indígena e a realidade excludente que projeta o PEIB. Sustentar, pois, uma noção de interculturalidade frente a um cenário de intervenção focalizado onde o resto da população não indígena não é integrado, é institucionalizar uma demagogia que posteriormente pode seguir aprofundando assimetrias com o resto da sociedade nacional, ao constituir-se como uma interculturalidade gueto, sem tocar o fundo político do assunto colonial. Carmen Montecino dá um aporte interessante neste sentido ao afirmar que:

Ao propor a Educação Intercultural Bilíngue como um programa especial destinado a satisfazer as necessidades de aprendizagem do setor indígena de nossa sociedade, a política faz responsável aos indígenas por conseguir uma sociedade pluralista. Conseguir uma sociedade pluralista, sem embargo, é um projeto político (é dizer, de redistribuição do poder). Curiosamente a política EIB permanece em silêncio frente aos processos sociais de exclusão e discriminação que articulam a construção 
social do indígena e do ser indígena no nosso país. (MONTECINOS, 2004, p. 34).

Neste sentido, assumir que, no Chile, quando falamos de EIB, falamos na verdade de Educação Indígena é um poderoso exercício de "sincerar" vontades.

Por sua vez, falar de educação indígena implica outra discussão importante, pois se faz imprescindível perspectivar se é educação para indígenas (Estado-indígenas) ou educação por indígenas. Apesar dos graus de participação que a EIB supõe dentro do mundo indígena, o Estado continua ostentando um poder tutelar e centralizador sobre como projetar este sistema. $\mathrm{O}$ apropriado para perspectivar uma educação é materializar o que dispõe o convênio 169 em seu artigo 27, de maneira que o Estado possa criar as condições necessárias (investimento, formação de professores, habilitação de espaços físicos, sociais e políticos etc.) para gestar uma educação indígena e progressivamente conceder o controle de sua educação de modo a constituir-se um grande e verdadeiro exercício de alteridade para com os povos.

Estabelecer uma educação indígena é gerar um novo gueto? Se pensarmos dentro de uma estrutura isolada, dentro do sistema educativo e dentro das margens políticas e jurídicas de negação em que se encontram imersos os povos indígenas no Chile, certamente pode se gerar um gueto, que pode se materializar em perigosos ressentimentos etnofóbicos e neomecanismos de exclusão cultural, social e política. Uma educação indígena, neste sentido, deve ser acompanhada de uma política intercultural abrangente que lide tanto com o jurídico, como com o educacional, conjugando de forma dialógica identidades, culturas, diferenças e diversidades.

No fundo o que está em jogo em uma educação de ou para po- 
vos indígenas, ou EIB, como propõe o Estado, é a pertinência para com seus educandos. Essa pertinência desde o indígena deve estar principalmente guiada pelos aspectos culturais (conhecimentos e saberes ancestrais) e linguísticos que eles mesmos consideram como elementares para a vivência e reprodução de suas culturas e povos. Estes devem ser integrados dentro de uma política de Estado nacional convergente e dialogante com os diferentes contextos e realidades culturais coexistentes, onde efetivamente se faça presente o “inter". Hoje, pois, oferecer uma educação intercultural para crianças indígenas, trabalhando a reafirmação de sua identidade, sem que a sociedade chilena seja à sua vez educada em autorreconhecer sua qualidade mestiça e a subvaloração imperante das outridades étnicas, propicia continuar reproduzindo a exclusão que por anos marginalizou as sociedades indígenas no país.

É por isso que hoje em dia sustentar uma educação intercultural e ademais bilíngue perspectivando só a população indígena e em contexto rural é não perceber que o mundo indígena também apresentou mudanças, que não são os mesmos que o estado deixou relegados em reduções há mais de 120 anos. Recordemos que mais de $70 \%$ hoje vive no meio urbano, portanto, uma demanda educativa e uma pertinência a respeito se constitui de modo diferente, e por isso também merece uma atenção diferente da que se está dando atualmente.

Neste sentido, uma concepção intercultural saudável necessariamente tem que se basear, como o Estado propõe na EIB, em uma relação de cooperação, e para que essa relação de cooperação não se transforme em caridade, há de estabelecer-se em relações de participação política efetiva, onde os povos indígenas não estejam apenas convocados à participação na implementação, como é 
o caso do PEIB, mas tanto no projeto de uma educação indígena, quanto no de uma educação intercultural. Isso pode assentar as bases políticas e ontológicas para começar a deixar de lado a subalternização de que por anos têm sido vítimas.

\section{Referências}

AYLWIN, José. El derecho internacional de los derechos humanos y los pueblos indígenas. In: - Las implicancias de la ratificación del Convenio $\mathbf{N}^{\circ} \mathbf{1 6 9}$ de la OIT en Chile. Santiago de Chile: Observatorio Ciudadano, 2010.

MINEDUC. Curriculum, Objetivos Fundamentales y Contenidos Mínimos Obligatorios de la Educación Básica y Media. Actualización 2005. Santiago de Chile: Ministerio de Educación, 2005.

. Curriculum, Objetivos Fundamentales y Contenidos Mínimos Obligatorios de la Educación Básica y Media. Actualización 2009. Santiago de Chile: Ministerio de Educación, 2009.

\section{- Orientaciones para comprender la implementación}

del sector de lengua indigena. 2011. Documento electrônico. Disponível em: <http:/Www.mineduc.cl/usuarios/intercultural/ doc/201104051251390.ORIENTACIONES\%20PARA \%20 SECTOR\%20DE\%20LENGUA\%20INDiGENA.pdf>. Acesso em: 3 ago. 2011.

MINEDUC; GARCÍA, Felino Choque. Manual Instructivo para la implementación del PEI intercultural. Santiago de Chile: Ministerio de Educación, República de Chile, 2011.

MONTECINOS, Carmen. Analizando la política de educación intercultural bilingüe en Chile desde la educación multicultural. Cuadernos Interculturales, Universidad de Valparaíso, Viña del Mar, v. 2, n. 3, p. 35-44, 2004. 
NACIONES UNIDAS. Declaración de las Naciones Unidas sobre los derechos de los pueblos indígenas. 2007. Disponível em: <http://www.un.org/esa/socdev/unpfii/documents/DRIPS es.pdf>. Acesso em: 3 ago. 2011.

OIT. Convenio 169: sobre pueblos indígenas y tribales en países independientes. Santiago de Chile: Oficina Internacional del Trabajo, OITCHILE, 2006.

RAMÍREZ, Boris. Colonialidade, Intercuturalidade e Educação: desdobramento na relação do povo Mapuche e o Estado do Chile. 2012. 174 f. Dissertação (Mestrado em Educação) - Programa de Pós-graduação em Educação, Centro de Ciências da Educação, Universidade Federal de Santa Catarina, Florianópolis, 2012.

REPUBLICA DE CHILE. Ley 19253. Establece normas sobre protección como fomento y desarrollo de los indígenas, y crea la corporación nacional de desarrollo indígena. 1993. Santiago de Chile. Disponível em: <www.leychile.cl/ navegar/?idnorma $=30620 \&$ idversion $=2008-05-09 \&$ idparte $>$. Acesso em: 25 mar. 2010.

SANTOS, Boaventura de Souza. Refundación del Estado en América Latina: Perspectivas desde una epistemología del sur. Lima: Instituto internacional de derecho y sociedad, IIDS, 2010.

WALSH, Catherine. (Re)Pensamiento Critico y (De)Colonialidad. In: Walsh, Catherine. (Org.) Pensamiento Critico y Matriz (De) colonial: Reflexiones Latinoamericanas. Quito: Abya Yala, 2005.

Interculturalidad y colonialidad del poder. Un pensamiento y posicionamiento "otro" desde la diferencia colonial. In: CASTRO-GÓMEZ, Santiago; GROSFOGUEL, Ramón (Orgs.). El giro decolonial: Reflexiones para una diversidad epistémica más allá del capitalismo global. Bogotá: 
Siglo del Hombre Editores, 2007.

. Interculturalidad, plurinacionalidad y decolonialidad: las insurgencias político-epistémicas de refundar el Estado. Tabula Rasa, Bogotá, n. 9, p. 131-152, 2008.

. Interculturaldade Crítica e Pedagogia Decolonial: insugir, re-existir e re-viver. In: CANDAU V. M. (Org.). Educação Intercultural na América Latina: entre concepções, tensões e propostas. Rio de Janeiro: 7 Letras, 2009. 


\section{Notas}

*Este trabalho é o fruto dos resultados da dissertação de mestrado Colonialidade, Intercuturalidade e Educação: Desdobramento na relação do povo Mapuche e o Estado do Chile (RAMÍREZ, 2012), desenvolvida no programa de PósGraduação em Educação da Universidade Federal de Santa Catarina.

** Professor de História e Ciências Sociais pela UAHC do Chile, mestre em Educação pela UFSC e doutorando em Educação pela UFBA. E-mail: $<$ piedragogo@gmail.com>.

${ }^{1}$ E o artigo segue assim: "O Estado reconhece como principais etnias do Chile a: Mapuche, Aimara, Rapa Nui ou Pascuenses, a das comunidades Atacameñas, Quechuas e Collas do norte do país, as comunidades Kawashkar ou Alacalufe e Yámana ou Yagán dos canais austrais. O Estado valora sua existência por serem parte essencial das raízes da Nação chilena, assim como sua integridade e desenvolvimento de acordo a seus costumes e valores." Entretanto, somente uma década mais tarde, outorgou-se o reconhecimento ao povo Diaguita.

${ }^{2}$ Para maior informação a respeito pode se consultar a carta da ONU "Pactos internacionais de D.H.” e as resoluções 1514, 1541 e 2625 da assembleia geral das nações unidas.

${ }^{3}$ É importante destacar que desde sua promulgação, em 1989, o convênio foi o primeiro e único instrumento internacional que reconhecia os direitos indígenas até a declaração dos direitos indígenas feita pela ONU em 2007. Mas ainda assim este instrumento para sua vinculação necessita ser ratificado pelos congressos dos países subscritores. Este processo se materializou no Chile apenas em $15 \mathrm{de}$ setembro de 2008 e entrou em vigor em 15 de setembro do ano seguinte.

${ }^{4} \mathrm{O}$ convênio 168 abarca, desde o artigo $26^{\circ}$ até o $31^{\circ}$, questões importante em educação que não estão presentes na Lei Indígena.

${ }^{5}$ Cabe destacar que o Chile votou a favor. Dentro dos artigos que vão desde o número 11 ao 15, dos 46 que a compõe, estão os que falam sobre educação e cultura indígena. Estes estão em relação direta com o que foi estabelecido pelo Convênio 169, mas queremos dar conta de um deles que guarda relação direta com nosso tema de estudo.

${ }^{6}$ Tal como sinala o sítio do programa, ele se inicia com cinco experiências piloto em regiões com maior densidade indígena. Através do apoio das universidades regionais, e por meio da intervenção de escolas focalizadas, buscou perspectivar orientações pertinentes à realidade cultural e linguística dos estudantes, bem como a geração de orientações que permitissem a contextualização do currículo e das práticas pedagógicas dos professores. Já no ano 2000 se realizou uma avaliação destas experiências ponderando os avanços e desafios para "começar a institucionalizar o PEIB como programa focalizado". Para o ano de 2001 surge uma nova iniciativa para complementar o programa que está dada por intermédio do programa homônimo PEIB-Origens, com o aporte do Banco Interamericano de Desenvolvimento (BID), para gerar propostas de intervenção pedagógicas e educativas no marco de 162 escolas. 